fisesta merkityksen muutoksesta. Fö ja sen morfologinen variantti $f e j$ esiintyvät suhteellisen usein vanhoissa paikannimissä, jotka liittyvät vuoriin ja kukkuloihin. Näistäkin nimityypeistä unkarilainen paikannimistöntutkija löytää asiakirjaesiintymiä 1200-1300-luvuilta.

\section{Lopuksi}

Lisätietoja halutessaan lukija voi tutustua lukukohtaisiin kirjallisuusluetteloihin, mutta kun itse tekstissä ei ole juurikaan viitteitä, on yksittäisen tiedon alkuperän jäljittäminen niin lukukohtaisen kirjallisuusluettelon kuin varsinaisen lähdeluettelonkin kautta hankalaa. Unkarinkielisten lähdeteosten nimet on kuitenkin lukijaa ajatellen käännetty englanniksi, joten lähdeluetteloa silmäilemällä saa unkarin kieltä taitamatonkin käsityksen siitä, mitä aiheita unkarilaisessa toponomastiikassa on käsitelty.

Teoksen laajasta kokonaisuudesta löytyy jokaiselle paikannimistöstä kiinnostuneelle jotakin. Etäiseksi suomalaiselle lukijalle saattaa jäädä asutusnimistöä käsittelevä osuus, mutta sen sijaan mikrotoponyymejä käsittelevä luku innostaa miettimään paikannimistön uralilaisia ja universaaleja kehityskulkuja.

Tilna Aalto

etunimi.k.sukunimi@helsinki.fi

Kirjoittaja on suomen kielen väitöskirjatutkija Helsingin yliopistossa.

\title{
Nollien tavanomaisuus ja tarpeellisuus
}

T. Givón: The story of zero. Amsterdam: John Benjamins Publishing Company 2017. 414 s. ISBN 978-90-272-1239-9.

Thomas (Talmy) Givónin teos The story of zero käsittelee nollaa kielessä ja mielessä laajasti ja monesta näkökulmasta. Givónin tavoitteena on osoittaa, että nolla on maailman kielissä tavallinen ja ettei ole olemassa yksiselitteistä nollakielten ryhmää. Givón on tuottelias pitkän linjan tutkija, mitä havainnollistaa se, että teoksen lähdeviitteistä löytyy peräti 47 hänen aiemmin julkaisemaansa tutkimusta. Argumentoidessaan Givón palaa usein aiempiin pohdintoihinsa ja avauksiinsa. Viittauksia ei ole ainoastaan tutkimuskirjallisuuteen vaan kirjaimellisesti myös keskusteluihin, joita hän on muiden lingvistien kanssa käynyt.

Kirjassa on esipuheen lisäksi 13 päälukua, kirjallisuusluettelo, asiasanasto sekä käsiteltyjen kielten luettelo. Teos jakautuu kahteen osaan. Osa I ("Natural zero") kattaa seitsemän ensimmäistä lukua ja paneutuu nolla-anaforaan yleisesti diskurssissa ja suhteuttaa sitä muihin anaforisiin viittauskeinoihin, etenkin pronomineihin. Nollan luonnollisuus osan I nimessä viittaa nollan tavanomaisuuteen ja luontevuuteen puheessa ja tekstissä. Luku pohtii yleisellä tasolla tutun tai ennakoitavan tiedon ja sen ilmaisemisen ja ilmaisematta jättämisen kognitiivisia perusteita. Osa II ("Structural zero") koostuu kuudesta luvusta, joissa nollia tarkastellaan syntakti- 
sesti rakenteiden näkökulmasta, etenkin erilaisissa alisteisissa lauseissa ja lopuksi myös adpositiolausekkeissa. Jonkin verran teoksessa käsitellään myös kataforisesti jäsentyviä nollia. Teosta sitovia ilmiöitä ovat referentiaalinen pääsy tarkoitteeseen, referentiaalinen jatkuvuus sekä topikaalisuus.

Teoksessa käsiteltyjä kieliä on paljon, lähes sata. Mukana on typologisesti erilaisia kieliä, mutta kaikkia mainittuja kieliä ei luonnollisestikaan käsitellä samassa laajuudessa. Yhtä unkarin kielen objekteihin liittyvää esimerkkiä lukuun ottamatta suomalais-ugrilaisia kieliä ei ole mukana. Vahvasti edustettuna on sen sijaan esimerkiksi uten kieli, joka on ollut Givónin tutkimuksissa keskeisessä roolissa ja josta hän on kirjoittanut kieliopinkin (2011). Teoksessa käsitellään verrattain runsaasti myös heprean, espanjan ja saksan nollailmiöitä, mutta eniten kiinnitetään huomiota englantiin, jonka kautta ilmiöitä yleensä esitellään. Puhutun ja kirjoitetun kielen eroja huomioidaan jonkin verran, mikä on perusteltua ja välttämätöntä, sillä anaforisten viittauskeinojen käyttö voi poiketa selvästikin puhutussa ja kirjoitetussa kielessä. Esimerkiksi suomessa pronomini- ja nollasubjektien työnjako on puheessa erilainen kuin kirjoituksessa (ks. esim. Väänänen 2016).

Esipuheessa Givón toteaa teoksen synnyn juontavan 1980-luvulle ja ideoihin niin sanotuista pro drop -kielistä. Pro drop -termi viittaa tavallisesti (pronomini)subjektin poisjättöön. Esimerkiksi suomen kielessä verbin persoonapääte voi osoittaa persoonan eikä pronominia tarvita (ks. Heinonen 1995). Jo johdannossa Givón painottaa, että pitää pro drop -termiä harhaanjohtavana ja yksipuolisena. Hänen mukaansa (s. 155) nollaanafora ei ole pro drop -kielten eksoottisuus vaan mitä luontevin kieliopillinen keino, jolla koodataan maksimaalista referentiaalista jatkuvuutta kielessä.

Fennistiikassa nolla liitettäneen tyypillisimmin nollapersoonaan, joka viittaa ilmisubjektittomiin ja tulkinnaltaan avoimiin yksikön kolmannen persoonan rakenteisiin (Laitinen 1995, 2006). Givónin syntaksin tutkimuksia tunnetaan fennistiikan piirissä, mutta niillä ei ole keskeistä roolia suomen nollapersoonan käsittelyissä (ks. esim. Laitinen 1995, 2006; ISK $\$$ 1347; Helasvuo \& Laitinen 2006; Jokela 2012), joskin muihin Givónin käsittelemiin nollailmiöihin löytyy viittauksia. On syytä huomata, että nollapersoonan kaltaiset rakenteet eivät ole tarkastelun kohteena tässä Givónin teoksessa, joka keskittyy nolla-anaforaan. Väänänen (2016) tarkastelee nimenomaan Givóniin (esim. 1983) tukeutuen pronominisubjektin poisjättöä yksikön ensimmäisessä persoonassa aineistonaan suomen vanhat murteet. Puhutun ja kirjoitetun suomen nollaanaforan ominaisuuksia tarkastelevat $\mathrm{Ha}$ kulinen ja Laitinen toteavat (2008: 162) Givóninkin aiempaan tutkimukseen viitaten, että anaforisen nollan valitseminen uudelleenmaininnan keinoksi edellyttää helppoa pääsyä puheenalaiseen tarkoitteeseen. Heidän mukaansa suomen nollaanaforalla on yhtymäkohtia 1. tai 2. persoonan persoonapronominien poisjätön kanssa, mutta kyse on kuitenkin kahdesta erillisestä ilmiöstä (mp.).

\section{Nollan luontevuus}

Kun viittaamme uudelleen edellä mainittuun, teemme valinnan erilaisten uudelleenmainintojen keinojen kesken. Nollan anaforisen käytön taustalla on ennakoitavan tiedon mainitsematta jättäminen. Givónin teoksen osan I luvut käsittelevät pääosin anaforista nollaa, jota suhteutetaan pronomineihin ja muihin viittauskeinoihin.

Givón lähtee luvussa 1 liikkeelle siitä, että nolla-anaforan kommunikatiivista logiikkaa on luontevinta tarkastella käyttökontekstissa. Tällöin nollaa voi verrata muihin referenssiä koodaaviin keinoihin, joita ovat erilaiset pronominit sekä defi- 
niittiset ja indefiniittiset NP:t. Diskurssissa indefiniittiset NP:t edustavat matalaa referentiaalista jatkuvuutta, nolla-anafora korkeaa referentiaalista jatkuvuutta (s. 6). Luvun 1 alussa käsitellään esimerkkiä, joka havainnollistaa painottoman anaforisen pronominin ja anaforisen nollan suhteita ja funktioita (s. 7): Esimerkissä John went to the mirror, [ø] examined his hair, [ø] sighed and [ø] turned nollat mahdollistavat referentiaalisen jatkuvuuden. Esimerkki voisi jatkua painottoman anaforisen pronominin sisältävällä vaihtoehdolla Then he walked out mutta ei anaforisen pronominin sisältävällä vaihtoehdolla Then [ø] walked out, vaikka molemmat ovat maksimaalisen referentiaalisen jatkuvuuden keinoja. Englannin kielessä nolla-anaforaa ei kuitenkaan voi käyttää virkerajan tai lausuman yli jälkimmäisen lauseen tapaan. Hakulinen ja Laitinen (2008: 168) huomauttavat, että suomessa nolla-anafora voi tietyin ehdoin esiintyä virkerajan yli kaunokirjallisessa tekstissä ja lausuman tai puheenvuoron rajan yli puhutussa kielessä.

Luvun 2 keskiössä on kieliopin ja tekstiä tuottavan ja tulkitsevan mielen suhde, jota tarkastellaan muistin aktivoitumisen ja uuden ja vanhan tiedon haun näkökulmista. Kyseessä ei ole anaforisten nollien paikantaminen, vaan luvussa käsitellään laajemmin pääsyä yhteiseen tietoon, jota kommunikaatiossa hyödynnämme. Kielten ja myös kulttuurien välisesti kiinnostavia ovat yhteisen tai jaetun kontekstin esimerkit, jotka saavat pohtimaan sitä, millä tavalla yhteinen tieto on kulttuurija kontekstiriippuvainen rakennelma. Jos joku esimerkiksi kertoo, että "välittäjä esitteli meille upeaa taloa, mutta olohuone oli liian pieni”, pystymme käsittelemään ja saavuttamaan tiedon olohuoneesta osittain siksi, että talosta ylipäätään on puhuttu juuri edellä, mutta myös siksi, että meillä on yhteistä kulttuurista tietoa siitä, että prototyyppisessä talossa on olohuone. (S. 37.) Huomattakoon, että englannin kie- lessä definiittisen tarkoitteen tuttuuteen liittyy myös määräinen artikkeli (the living room). Kokonaisuutena luku 2 on taustoittava ja liikkuu melko kaukana nollaanaforista, mutta sen yhteys nollailmiöihin syntyy siitä, mitä tietoa voidaan jättää pois milläkin perusteella ja mikä on tunnettua tai tärkeää.

Luvut 3 ja 4 keskittyvät anaforisten pronominien ja verbaalisen persoonanmerkinnän taustalla vaikuttaviin diakronisiin prosesseihin. Luku 4 on käytännössä tapaustutkimusmainen katsaus uten kielen pronomineista, ja luvusta on ilmestynyt aiempia versioita toisaalla. Luvussa 5 Givón problematisoi generatiivisen kieliopin formalistista näkemystä, jonka mukaan vain tietyt kielet ovat pro drop -kieliä ja nollakielet ovat sidoksissa sanajärjestyksen vapauteen. Puhutun englannin aineiston avulla hän purkaa käsitystä nollaanaforan eksoottisuudesta ja englannista kielenä, jossa nollailmiöt ovat hyvin rajallisia. Givón korostaa sitä, että puhutussa englannissa merkittävä osa subjekteista on nollia. Luvun lopussa (s. 156) hän huomauttaakin aiheellisesti, että lingvistit eivät voi pohjata teorioita luonnollisesta kielestä normitettuun, kirjoitettuun englantiin. Tämä on tärkeä viesti koko teoksen kannalta.

Luvussa 6 käsitellään verbiä nollana itsenäisissä predikaatittomissa lauseissa (verbless clause). Anaforiset nollat lienevät tutuimpia syntaktisesti suhteellisen selvien subjektien ja objektien tarkastelussa, johon Givóninkin teoksen alkupuoli painottuu. Siksi luvun 6 verbaaliset nolla-anaforat voivat yllättää lukijan, joskin Givón (s. 157) toteaa tutkineensa niitä ennenkin. Hän tarkastelee verbaalisina nolla-anaforina muun muassa pyyntöjä, jotka rakentuvat pelkästä NP:stä (esim. kirurgin lausuma Pihdit!). Ilmiötä perustellaan varsin monipuolisen esimerkkiaineiston valossa, sillä luvussa käsitellään verbittömiä ilmaisuja muun muassa puhutussa uten kielessä, puhutussa englannissa, 
lapsenkielessä ja pidginkielissä. Kaiken kaikkiaan puhuttua kieltä tarkastellaan teoksessa melko paljon, mutta toisaalta puhutun ja kirjoitetun kielen eroja nollan kannalta ei ole koontimaisesti käsitelty.

Luku 7 paneutuu passiiveihin ja antipassiiveihin, joissa nolla signaloi siitä, että puheenaihe on muualla kuin subjektin tai objektin tarkoitteessa. Agentti edustuu Givónin mukaan nollana passiivirakenteissa (esim. two months later, she was fired [by ø]) ja samoin objekti antipassiivisissa rakenteissa (esim. he eats [ø] regularly). Molemmissa nollissa motivaationa on niiden irrelevanttius diskurssissa.

\section{Nolla rakenteissa}

Osa II tarkastelee nollaa ja sen vastineita erilaisissa alisteisissa lauseissa ja nominaalisissa rakenteissa. Diakroninen näkökulma kulkee mukana syntaktissemanttisten suhteiden tarkastelussa. Luvuissa 8-10 käsitellään relatiivilauseita, adverbiaalilauseita ja infiniittisiä rakenteita. Pää- ja sivulauseiden tai nominaalisten rakenteiden nollien tarkastelussa tärkeä ilmiö on sama- ja erisubjektisuus. Se tarjoaa antoisan näkökulman myös suomen lauseenvastikkeiden tarkasteluun, sillä niissä subjekti voi toisinaan olla sama ja toisinaan eri kuin päälauseessa, ja tällä on merkitystä subjektia merkitsevien elementtien, kuten possessiivisuffiksin käytön, kannalta (esim. tiedän olevani turkulainen vs. tiedän sinun olevan turkulainen).

Luvussa 11 nollaa ja siihen suhteutuvia pronomineja tarkastellaan yhdyslauseissa refentiaalisen jatkuvuuden rakentajina. Luku 12 käsittelee nollaa infiniittisissä subjektittomissa rakenteissa. Ilman kontekstia esimerkiksi tarkoitusta ilmaisevien lauseiden ja rakenteiden nolla voi olla monitulkintainen. Lause she left him to eat dinner voidaan tulkita joko tavalla a) 'she left him so that she could eat (her) dinner' tai b) 'she left him so that he could eat (his) dinner' (s. 323). Käytännössä kontekstin ja syntaktisten vihjeiden merkitys on suuri. Tällaiset esimerkit ovat moniulotteisia myös suomen kielen kannalta, kun käytössä on yksi persoonapronomini eri sukupuolille. Erilaisten pronominiryhmien ja muiden viittausten vertailuun suomen kaltainen kieli, jossa ei ole kieliopillista sukua, olisi ylipäätään hyvä lisä tässäkin teoksessa.

Luku 13 käsittelee erityyppisten lauseiden adpositiorakenteita - oikeastaan "irrallisia" adpositioita, joiden nominaalinen argumentti on nolla (the woman he talked to $[\varnothing])$. Esimerkkitapausten kautta selvitetään näiden adpositioiden typologiaa sekä muutamien eri kielten sanajärjestyksen kehitysvaiheita ja verbiaffikseja.

\section{Nollien tarina}

The story of zero tarkastelee nollailmiöitä monipuolisesti, erityyppisten aineistojen ja kielten valossa. Näkökulmia ja osioita on runsaasti, joten kiinnostavaa luettavaa löytyy sekä nollailmiöihin syventyneille että toisaalta ilmiöistä vähemmän tietäville. Lukijalle siirtymät ilmiöstä toiseen yhdistettynä esimerkkien runsauteen ovat välillä melko haastavia. Esimerkkien paljouden lisäksi paikoin vain muutaman virkkeen pituiset alaluvut tekevät kokonaisuudesta hieman pirstaleisen.

Teos kuvaa nollaa kieliin laajasti ja perustavasti kuuluvana ilmiönä, ja teos itsessään on laaja ja perusteellinen. Perinteisesti esimerkiksi fennistille nollaanaforien tarkastelu on tutuinta tietyissä syntaktisissa asemissa, kuten subjekteina tai objekteina. Tästä syystä yhtymäkohtien hahmottaminen kaikkien teoksessa käsiteltävien nollailmiöiden välille voi vaatia jonkin verran totuttelua.

The story of zero herättää paljon ajatuksia ja laajentaa näkökulmaa nollailmiöihin. Teokseen voi palata hakuteosmaisesti ja toisaalta omien ajatusten herättelijänä. 


\author{
HANNA JOKELA \\ etunimi.sukunimi@utu.fi \\ Kirjoittaja on yliopistonlehtori suomen \\ kielen ja kulttuurin (ei-äidinkielisille) \\ oppiaineessa Turun yliopistossa.
}

\section{Lähteet}

Givón, T. 1983: Topic continuity in discourse. A quantitive cross-language study. Amsterdam: John Benjamins.

_ 2011: Ute reference grammar. Amsterdam: John Benjamins.

Hakulinen, Auli - Laitinen, Lea 2008: Anaforinen nolla. Kielioppia ja affekteja. - Virittäjä 112 s. 162-185.

Heinonen, Tarja Rittta 1995: Null subjects in Finnish. From either-or to more-or less. - Tapio Hokkanen, Marja Leinonen \& Susanna Shore (toim.), SKY journal of linguistics 1995 s. 47-78. Helsinki: Suomen kielitieteellinen yhdistys.

Helasvuo, Marja-Liisa - Laitinen, LEA 2006: Person in Finnish. Paradigmatic and syntactic perspectives. - Marja-Liisa Helasvuo \& Lyle Campbell (toim.), Grammar from the human perspective. Case, space, and person in Finnish s. 173-208. Amsterdam: John Benjamins.
ISK = Hakulinen, Auli - Vilkuna, Maria - Korhonen, Rittta Koivisto, Vesa - Heinonen, Tarja RittTa - Alho, IrJa 2004: Iso suomen kielioppi. Suomalaisen Kirjallisuuden Seuran Toimituksia 950. Helsinki: Suomalaisen Kirjallisuuden Seura.

Jokela, Hanna 2012: Nollapersoonalause suomessa ja virossa. Tutkimus kirjoitetun kielen aineistosta. Turun yliopiston julkaisuja, Annales Universitatis Turkuensis C 334. Turku: Turun yliopisto. http://urn.fi/ URN:ISBN:978-951-29-4912-o.

LAitinen, LEA 1995: Nollapersoona. - Virittäjä 99 s. 337-358.

_ 2006: Zero person in Finnish. A grammatical resource for construing human reference. - Marja-Liisa Helasvuo \& Lyle Campbell (toim.), Grammar from the human perspective. Case, space, and person in Finnish s. 209-233. Amsterdam: John Benjamins.

VÄÄNÄNEN, Milja 2016: Subjektin ilmaiseminen yksikön ensimmäisessä persoonassa. Tutkimus suomen murteista. Turun yliopiston julkaisuja, Annales Universitatis Turkuensis C 430 . Turku: Turun yliopisto. http://urn.fi/ URN:ISBN:978-951-29-6664-6.

\section{Empiiristä kognitiivista kielitiedettä}

Milla Luodonpää-Manni, Esa Penttilä \& Johanna Viimaranta (toim.): Empirical approaches to cognitive linguistics. Analyzing real-life data. Newcastle upon Tyne: Cambridge Scholars Publishing 2017. 350 s. ISBN 978-1-4438-7325-3. 1970-luvulla formaaliseen kielenkuvauksen perinteeseen reaktiona syntyneellä kognitiivisella kielentutkimuksella on Suomessa pitkä traditio. Sen teorioita ja menetelmiä on hyödynnetty erityisesti fennistiikassa monipuolisesti 1980-1990-lukujen vaih- 